\title{
On-line Preconcentration and Determination of Traces of Lead in River-water and Seawater by Flow Injection-Flame Atomic Absorption Spectrometry and ICP-Mass Spectrometry
}

\author{
Tatsuya SeKI, * Yoshihiro Hirano, ${ }^{* *}$ and Koichi OgUma**† \\ *Analysis Research Department, Chemical Research Laboratories, Nissan Chemical Industries, Ltd., \\ Tsuboi-cho, Funabashi 274-8507, Japan \\ **Department of Materials Technology, Faculty of Engineering, Chiba University, \\ Yayoi-cho, Inage, Chiba 263-8522, Japan
}

(Received July 12, 2001; Accepted November 19, 2001)

Lead is well known as one of the most toxic metals and noted in the field of environmental chemistry. ${ }^{1}$ The concentration of lead in natural water is extremely low (sub ppb level) so that some preconcentration step must be included to assure the sensitivity of a conventional instrument employed in the final measurement step of analysis. Furthermore, the blank value introduced from the reagents or from the laboratory environment must be kept at as low level as possible in order to obtain the precise analytical results for traces of lead.

Flow injection (FI) on-line preconcentration procedures now play an important role in trace metal analysis. ${ }^{2-6}$ The advantages of the combination of FI on-line preconcentration with spectrometry have been reviewed in the previous paper. Various adsorbents have so far been reported for the on-line preconcentration of lead (and other heavy metals) in water samples. For example, 8-hydroquinoline immobilized onto silicone tubing ${ }^{8}$ or microporous silica, ${ }^{9}$ poly(L-cysteine) immobilized controlled-porous glass, ${ }^{10}$ a highly cross-linked macroporous iminodiacetate resin (Metpac CC-1, Dionex) $)^{11}$ and dealginated seaweed ${ }^{12}$ have been used for the on-line preconcentration of lead in water samples prior to the ICP-MS determination of lead. A flow injection system has been also described for the tungsten coil atomic absorption spectrometric determination of lead in water samples using sorption of the diethyldithiocarbamate complex into a fullerene $\left(\mathrm{C}_{60}\right)$ microcolumn. ${ }^{13}$ However, all of the adsorbents mentioned above are not so selective, so the recovery of lead is much more affected by matrix elements.

In 1994, a lead-selective chromatographic resin was developed by Horwitz et al. ${ }^{14}$ The resin was prepared by impregnating Amberchrom CG-71md resin (Supelco) with an isodecanol solution of bis-4,4'(5')-[tert-butylcyclohexano]-18crown-6 and it is now commercially available as $\mathrm{Pb} \cdot \mathrm{Spec}^{\mathrm{TM}}$ (EIChrom Industries, Darien, IL). $\mathrm{Pb} \cdot \mathrm{Spec}^{\mathrm{TM}}$ exhibits high selectivity to lead(II) and shows no affinity for the alkali metal ions and other heavy metal ions, ${ }^{14}$ therefore, the resin has been successfully applied by the present authors to preconcentration of lead in steel by an FI technique. ${ }^{7}$ This work was undertaken to extend the excellent utility of $\mathrm{Pb} \cdot \mathrm{Spec}^{\mathrm{TM}}$ to the precise

† To whom correspondence should be addressed.

E-mail: oguma@galaxy.tc.chiba-u.ac.jp determination of traces of lead in river-water and seawater by FI on-line preconcentration coupled with flame atomic absorption spectrometry (FAAS) or ICP-mass spectrometry (ICP-MS).

\section{Experimental}

\section{Reagents}

A standard lead(II) solution $(1000 \mu \mathrm{g} / \mathrm{ml})$ for AAS (Kanto Chemicals, Tokyo) was used to prepare the working solutions for construction of the calibration curve. A standard solution $(1000 \mu \mathrm{g} / \mathrm{ml})$ for AAS of strontium(II) was also purchased from Kanto Chemicals, Tokyo.

Lead-selective chromatographic resin $\mathrm{Pb} \cdot \mathrm{Spec}^{\mathrm{TM}}$ (EIChrom Industries, Darien, IL) was used as column packing for preconcentration of $\mathrm{Pb}$ (II).

Nitric acid for electronics industry use (Kanto Chemicals, Tokyo), sulfuric acid of Ultrapur grade (Kanto Chemicals, Tokyo) and ammonium oxalate of analytical reagent grade (Komune Chemicals, Tokyo) were used as received.

Water purified by a Milli-Q SP ICP-MS (Nihon Millipore, Tokyo) was used throughout the work.

\section{Apparatus}

The FI system for the AAS determination of lead is the same one as used for the determination of lead in steel. ${ }^{7}$ A diagram of the FI system with ICP-MS detection is illustrated in Fig. 1. Both the flow systems were assembled from 1-mm bore Teflon tubing and connectors. A Hitachi L-6010 Pump (Hitachi, Tokyo) was used to pump the eluent $(0.1 \mathrm{M}$ ammonium oxalate or sulfuric acid solution) and a Microtube Pump MP-3 (Tokyo Rikakikai, Tokyo) was used to deliver sample and washing solutions to the preconcentration column for lead.

The preconcentration column was prepared by packing an appropriate amount of $\mathrm{Pb} \cdot \mathrm{Spec}^{\mathrm{TM}}$ in a PEEK column $(7.5 \mathrm{~mm}$ i.d. $\times 100 \mathrm{~mm}$ for AAS detection and $7.5 \mathrm{~mm}$ i.d. $\times 50 \mathrm{~mm}$ for ICP-MS detection).

A Shimadzu Model AA-6400F atomic absorption spectrophotometer was fitted with a deuterium background corrector and an optional analog output unit, and used under the same conditions as described in the previous paper.' Background correction was performed for all measurements. A 


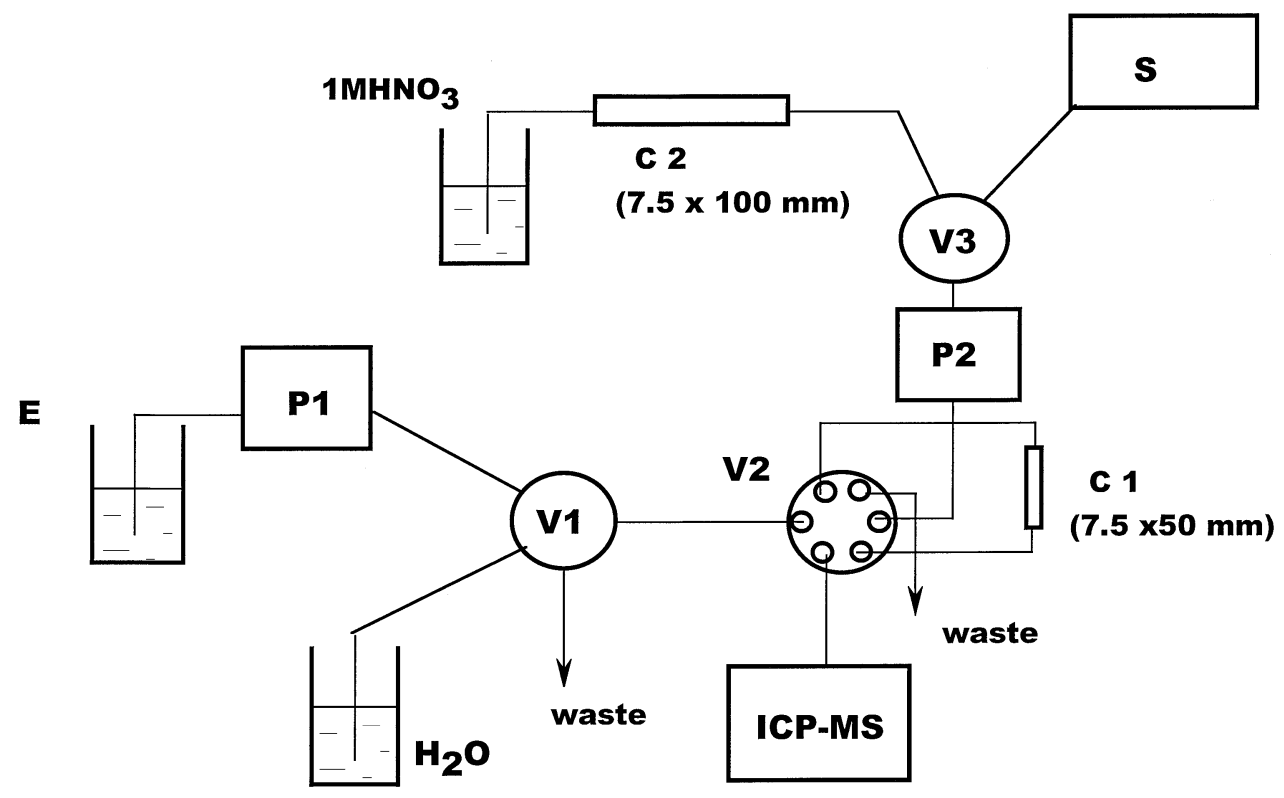

Fig. 1 Block diagram of the flow injection system for determination of lead by ICP-MS detection. E, eluent (0.1 $\left.\mathrm{M} \mathrm{H}_{2} \mathrm{SO}_{4}\right)$; P1, HPLC pump; P2, peristaltic pump; V1, V2, and V3, six-way valves; $\mathrm{C} 1$ and $\mathrm{C} 2, \mathrm{~Pb} \cdot \mathrm{Spec}^{\mathrm{TM}}$ column; $\mathrm{S}$, sample.

Table 1 Operating conditions of ICP-MS

\begin{tabular}{ll} 
ICP-MS & Seiko Instruments SPQ9000 \\
Plasma conditions & \\
Rf power & $1.0 \mathrm{kw}$ \\
Nebulizer gas flow & $1.0 \mathrm{~L} / \mathrm{min}$ \\
Plasma gas flow & $16.0 \mathrm{~L} / \mathrm{min}$ \\
Auxiliary gas flow & $1.0 \mathrm{~L} / \mathrm{min}$ \\
Sampling conditions & \\
Sampling depth & $10 \mathrm{~mm}$ \\
Sampling cone & Copper, $0.80 \mathrm{~mm}$ orifice diameter \\
Skimmer cone & Copper, $0.40 \mathrm{~mm}$ orifice diameter \\
Measured isotope & ${ }^{208} \mathrm{~Pb}$ \\
\hline
\end{tabular}

72R chart recorder (Gasukuro Ind. Co., Tokyo) was employed to record FIA signals. A noise filter Signal Cleaner SC77 (System Instruments, Tokyo) was mounted between the analog recorder and the AAS to reduce signal noise and was used with a pass peak of $51 \mathrm{~s}$.

A Seiko Instruments SPQ9000 ICP-MS (Seiko Instruments, Chiba, Japan) was also used to detect traces of lead under the conditions described in Table 1 .

\section{Procedure}

Preparation of sample solutions. About $25 \mathrm{~g}$ of river-water certified reference material, JAC0032 (metals added, The Japan Society for Analytical Chemistry, Tokyo), was taken. After addition of $2.3 \mathrm{ml}$ of nitric acid, the sample solution was gently boiled for $10 \mathrm{~min}$ and then cooled to room temperature before FIA with FAAS detection. For the analyses of river-water certified reference material, JAC0031 (metals not added, The Japan Society for Analytical Chemistry, Tokyo) and seawater certified reference material, BCR CRM403 (Community Bureau of Reference, Brussels), about 5 to $20 \mathrm{~g}$ of the sample was taken. An appropriate amount of nitric acid was added to give 1 $\mathrm{M}$ nitric acid solution and the resulting solution was gently boiled for $10 \mathrm{~min}$, followed by its cooling and FIA with ICPMS detection.

\section{Determination of lead}

The $\mathrm{Pb} \cdot \mathrm{Spec}^{\mathrm{TM}}$ column was conditioned with $1 \mathrm{M}$ nitric acid (3 $\mathrm{min} / \mathrm{min}$ ) for $2 \mathrm{~min}$. The sample solution prepared as described above was then passed through the column $(3 \mathrm{ml} / \mathrm{min})$ to adsorb lead on the column. After washing the column with 1 $\mathrm{M}$ nitric acid ( $3 \mathrm{~min} / \mathrm{min}$ ) for $2 \mathrm{~min}$, lead was eluted by passing $0.1 \mathrm{M}$ ammonium oxalate solution $(4 \mathrm{ml} / \mathrm{min}, 3 \mathrm{~min}$ ) for AAS detection or $0.1 \mathrm{M}$ sulfuric acid ( $3 \mathrm{ml} / \mathrm{min}, 4 \mathrm{~min}$ ) for ICP-MS detection through the column from the opposite direction of the sample stream. The effluent was directly introduced to the nebulizer of the atomic absorption spectrophotometer or ICPmass spectrometer. The peak height was used for quantification. The calibration curves were constructed over the concentration ranges of 0.1 to $10 \mu \mathrm{g}$ of lead for FI-AAS and 0.1 to $10 \mathrm{ng}$ of lead for FI-ICP-MS, respectively.

\section{Results and Discussion}

On-line preconcentration of lead on $\mathrm{Pb} \cdot \mathrm{Spec}^{T M}$

$\mathrm{Pb} \cdot \mathrm{Spec}$ is the trade name of the resin which was first prepared and introduced as a solid-phase extractant by Horwitz et al. ${ }^{14}$ in $1994 . \mathrm{Pb} \cdot \mathrm{Spec}^{\mathrm{TM}}$ shows high selectivity to lead in nitric acid media, giving $k^{\prime}$ of almost 1000 for lead at $1 \mathrm{M}$ nitric acid. Among the metal ions tested by Horwitz et al., strontium(II) and thallium(I) have $k^{\prime}$ of $c a .20$ and barium(II) has $k^{\prime}$ of $c a$. 10 . Sodium(I), potassium(I), calcium(II), magnesium(II), iron(III), aluminum(III) and titanium(IV) show practically no adsorption on $\mathrm{Pb} \cdot \mathrm{Spec}^{\mathrm{TM}} .{ }^{14}$ The high $k^{\prime}$ and high selectivity for lead(II) on $\mathrm{Pb} \cdot \mathrm{Spec}$ prompted us to use the resin for the effective separation and preconcentration of $\mathrm{Pb}$ (II) in FIAAS determination of lead in steel. ${ }^{7}$

In this work, we tried to extend the applicability of the adsorbent to the FAAS and ICP-MS determination of traces of lead in river-water and seawater. Strontium(II) is somewhat more weakly adsorbed on $\mathrm{Pb} \cdot \mathrm{Spec}^{\mathrm{TM}}$ than lead(II). ${ }^{14}$ The oceanic mean concentration of strontium is $7.8 \mathrm{mg} / \mathrm{kg}^{15}$ and fresh water usually contains far less strontium. Therefore we 


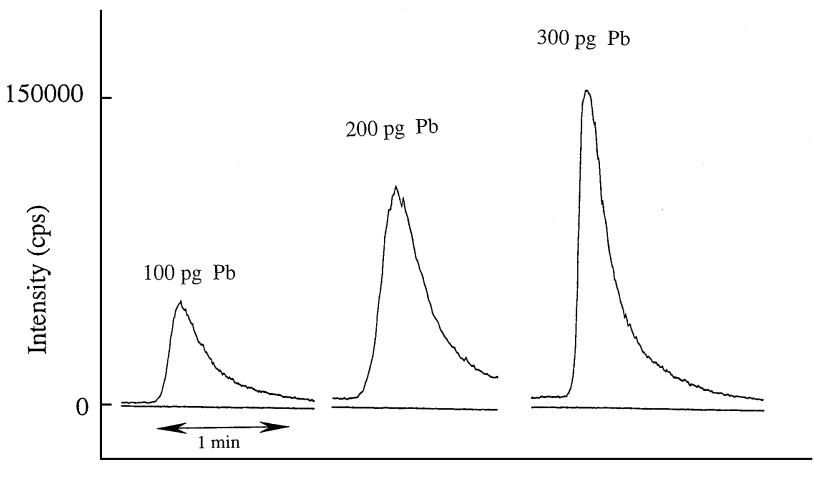

Fig. 2 FI signals for standard lead(II) solutions by ICP-MS detection.

examined the effect of strontium on the determination of lead. The results revealed that 100 to $500 \mu \mathrm{g}$ of strontium(II) gave no effects on the peak height for $1 \mu \mathrm{g}$ of lead(II) in $10 \mathrm{ml}$ of $1 \mathrm{M}$ nitric acid solution and $1000 \mu \mathrm{g}$ of strontium(II) reduced the peak height for lead(II) to $77 \%$ of that for lead(II) alone. Based on these observations, it was concluded that the present method would be applicable to the analysis of seawater.

In the previous work, ${ }^{7} 5 \mu \mathrm{g}$ of lead(II) was quantitatively retained on a $\mathrm{Pb} \cdot \mathrm{Spec}^{\mathrm{TM}}$ column $(7.5 \mathrm{~mm}$ i.d. $\times 100 \mathrm{~mm})$ and eluted with $0.1 \mathrm{M}$ ammonium oxalate solution. The detection limit equivalent to $3 \sigma$ of the background signal with FAAS detection was found to be $0.05 \mu \mathrm{g}$ lead, so that the detection limit in concentration is $0.5 \mathrm{ppb}$ lead when $100 \mathrm{ml}$ of a sample solution is injected. The detection limit is not sufficient to determine lead in non-polluted natural waters at several ten ppt level. Therefore, ICP-MS was employed to determine lead in river-water (certified reference material JAC0031, The Japan Society for Analytical Chemistry) and seawater (certified reference material BCR CRM403, Community Bureau of Reference, Brussels).

When ICP-MS was used for the lead detection, the problem was induced by lead impurities included in solutions used for column washing and lead elution. About $0.1 \mathrm{M}$ ammonium oxalate solution and $1 \mathrm{M}$ nitric acid were found to contain 0.1 ppb and $0.5 \mathrm{ppt}$ lead, respectively. We tried to purify ammonium oxalate solution and could not find an appropriate purification method. Therefore, we used $0.1 \mathrm{M}$ sulfuric acid as an eluent for ICP-MS detection of lead because it was found to contain far less lead as an impurity. Sulfuric acid showed weaker elution power for lead than ammonium oxalate, so that a $\mathrm{Pb} \cdot \mathrm{Spec}^{\mathrm{TM}}$ column for preconcentration of lead was shortened from $100 \mathrm{~mm}$ to $50 \mathrm{~mm}$ to reduce the elution time. Furthermore a $\mathrm{Pb} \cdot \mathrm{Spec}^{\mathrm{TM}}$ column was added for on-line purification of $1 \mathrm{M}$ nitric acid between a $1 \mathrm{M}$ nitric acid reservoir and a $\mathrm{Pb} \cdot \mathrm{Spec}^{\mathrm{TM}}$ column for preconcentration of lead (see Fig. 1). These modifications enabled us to determine lead in natural waters at ppt level.

Figure 2 shows the FI signals obtained for standard lead solutions by ICP-MS detection. The detection limit equivalent to $3 \sigma$ of the background noise by ICP-MS detection is $0.02 \mathrm{ng}$. This means that the sensitivity of the proposed FI on-line preconcentration coupled with ICP-MS detection is about 2500 times higher than that coupled with FAAS detection.

\section{Determination of lead in river water and seawater}

To examine the accuracy and precision of the proposed methods, they were applied to the analysis of river water reference materials provided by the Japan Society for Analytical
Table 2 Determination of lead in river-water certified reference material, JAC0031 a, by FI preconcentration and ICPMS detection

\begin{tabular}{cccccc}
\hline Run & $\begin{array}{c}\text { Sample } \\
\text { taken/g }\end{array}$ & $\begin{array}{c}\mathrm{Pb} \text { added/ } \\
\text { ng }\end{array}$ & $\begin{array}{c}\mathrm{Pb} \text { found/ } \\
\text { ng }\end{array}$ & $\begin{array}{c}\text { Content } \\
\text { in ng }\end{array}$ & $\begin{array}{c}\text { Original sample, } \\
\text { ppt }\end{array}$ \\
\hline 1 & 5.4 & 0 & 0.12 & 0.12 & 22 \\
2 & 11.7 & 0 & 0.26 & 0.26 & 22 \\
3 & 19.2 & 0 & 0.36 & 0.36 & 19 \\
4 & 9.4 & 0.10 & 0.30 & 0.20 & 21 \\
5 & 12.0 & 0.20 & 0.47 & 0.27 & 22 \\
6 & 12.6 & 0.30 & 0.57 & 0.27 & 21 \\
& & & & & av. $21.3 \pm 1.1$ \\
\hline
\end{tabular}

a. Certified value: $26 \pm 3 \mathrm{ppt}$.

Table 3 Determination of lead in river-water certified reference material, JAC0032 $2^{\mathrm{a}}$, by FI preconcentration and FAAS detection

\begin{tabular}{cccc}
\hline Run & $\begin{array}{c}\text { Sample taken/ } \\
\mathrm{g}\end{array}$ & $\begin{array}{c}\mathrm{Pb} \text { found/ } \\
\mu \mathrm{g}\end{array}$ & $\begin{array}{c}\text { Content in original sample, } \\
\mathrm{ppb}\end{array}$ \\
\hline 1 & 24.3 & 0.227 & 9.3 \\
2 & 22.8 & 0.214 & 9.4 \\
3 & 23.0 & 0.214 & 9.3 \\
& & & av. $9.3 \pm 0.0_{6}$ \\
\hline
\end{tabular}

a. Certified value: $9.9 \pm 0.2 \mathrm{ppb}$.

Table 4 Determination of lead in seawater certified reference material, BCR CRM403 ${ }^{\text {a }}$, by FI preconcentration and ICP-MS detection

\begin{tabular}{cccc}
\hline Run & $\begin{array}{c}\text { Sample taken/ } \\
\mathrm{g}\end{array}$ & $\begin{array}{c}\text { Pb found/ } \\
\mathrm{ng}\end{array}$ & $\begin{array}{c}\text { Content in original sample, } \\
\mathrm{ppb}\end{array}$ \\
\hline 1 & 15.27 & 0.42 & 28 \\
2 & 8.24 & 0.21 & 25 \\
3 & 6.78 & 0.22 & 32 \\
4 & 4.64 & 0.11 & 24 \\
& & & av. $27.3 \pm 3.6$ \\
\hline
\end{tabular}

a. Certified value: $24.24 \pm 5.18 \mathrm{ppb}$.

Chemistry and seawater reference material provided by Community Bureau of Reference. The results obtained are summarized in Tables 2 to 4 . The analytical values obtained for the river-waters are slightly lower than the certified values, although the precision is satisfactory. This is probably because some portion of lead(II) in the river-water samples analyzed exists as the complexes which are not retained on the $\mathrm{Pb} \cdot \mathrm{Spec}^{\mathrm{TM}}$ column. The values for the seawater are in good agreement with the certified value.

\section{References}

1. S. E. Manahan, "Environmental Chemistry", 6th ed., 1994, Chap. 7, CRC Press, Boca Raton.

2. M. Valcarcel and M. D. Luque de Castro, "NonChromatographic Continuous Separation Technique", 1991, The Royal Society of Chemistry, Cambridge.

3. Z. Fang, "Flow Injection Separation and Preconcentration", 1993, VCH, Weinheim.

4. J. L. Burguera (ed.), "Flow Injection Atomic Spectroscopy", 1989, Marcel Dekker, New York.

5. Z. Fang, S. Xu, and G. Tao, J. Anal. At. Spectrom., 1996, 11,1 . 
6. M. D. Luque de Castro and L. Gamiz-Gracia, Ad. Atom. Spectrosc., 1998, 4, 177.

7. T. Seki, H. Takigawa, Y. Hirano, Y. Ishibashi, and K. Oguma, Anal. Sci., 2000, 16, 513.

8. S. N. Willie, H. Tekgul, and R. R. Sturgeon, Talanta, 1998 47, 439.

9. S. D. Lofthouse, G. M. Greenway, and S. C. Stephen, J. Anal. At. Spectrom., 1999, 14, 1839.

10. M. Howard, H. A. Jurbergs, and J. A. Holcombe, J. Anal. At. Spectrom., 1999, 14, 1209.
11. M. Nicolai, C. Rosin, N. Tousset, and Y. Nicolai, Talanta, 1999, 50, 433.

12. M. E. Romero-Gonzalez, C. J. Williams, and P. H. E. Gardiner, J. Anal. At. Spectrom., 2000, 15, 1009.

13. M. M. Silva, M. A. Z. Arruda, F. J. Krug, P. V. Oliveira, Z. F. Queiroz, M. Gallego, and M. Valcarcel, Anal. Chim. Acta, 1998, 368, 255.

14. E. P. Horwitz, M. L. Dietz, S. Rhoads, C. Felinto, N. H. Gale, and J. Houghton, Anal. Chim. Acta, 1994, 292, 263.

15. Y. Nozaki, Eos, Trans. AGU, 1997, 78, 221. 